\title{
Contents IMIA Yearbook of Medical Informatics 2020
}

\author{
President's Statement S. Koch \\ President's Statement \\ Obituaries E. Hovenga, J. Ronald, L. Westbrooke, D. Skiba \\ Remembering - Joan Edgecumbe (1942-2019) \\ R. Beuscart, J. Bouaud, M.-C. Jaulent, B. Séroussi \\ Vassilis Koutkias (1975 - 2019) - the Painful Loss of a Rare Person \\ Editorial K. Fultz Hollis, L. F. Soualmia, B. Séroussi \\ Transparency of Health Informatics Processes as the Condition of Healthcare Professionals' \\ and Patients' Trust and Adoption:the Rise of Ethical Requirements \\ IAHSI Papers R. Haux, M. J. Ball, M Kimura, F Martin-Sanchez, P. Otero, E. Huesing, S. Koch, C. U. Lehmann \\ The International Academy of Health Sciences Informatics (IAHSI): IMIA's Academy is Now \\ Established and on Track \\ F. Martin-Sanchez, M. J. Ball, M. Kimura, P. Otero, E. Huesing, C. U. Lehmann, R. Haux \\ International Academy of Health Sciences Informatics (IAHSI): Strategy and Focus Areas, Ist Version \\ Keynote K. W. Goodman \\ Ethics in Health Informatics
}

Special Section:

Ethics in Health Informatics

Survey H. K. Galvin, P. R. DeMuro

Developments in Privacy and Data Ownership in Mobile Health Technologies, 2016-2019

Working Group Contributions

C. E. Kuziemsky, I. Hunter, S. B. Gogia, S. lyenger, G. Kulatunga, V. Rajput, V. Subbian, 0. John, A. Kleber, H. F. Mandirola, J Florez-Arango, N. Al-Shorbaji, S. Meher, J. G. Udayasankaran, A. Basu Ethics in Telehealth: Comparison between Guidelines and Practice-based Experience the Case for Learning Health Systems

S.-T. Liaw, H. Liyanage, C. Kuziemsky, A. L. Terry, R. Schreiber, J. Jonnagaddala, S. de Lusignan

Ethical Use of Electronic Health Record Data and Artificial Intelligence: Recommendations

of the Primary Care Informatics Working Group of the International Medical Informatics Association

L. W. Peute, V. Lichtner, M. T. Baysari, M. Hägglund, J. Homco, S. Jansen-Kosterink, I. Jauregu, J. Kaipio, C. E. Kuziemsky, E. C. Lehnbom, F. Leite, B. Lesselroth, D. Luna, C. Otero, R. Pedersen, S. Pelayo, R. Santos, N.-A. Silva, M. Tyllinen, L. Van Velsen, W. Y. Zheng, M. Jaspers, R. Marcilly Challenges and Best Practices in Ethical Review of Human and Organizational Factors Studies in Health Technology: a Synthesis of Testimonies

0. Rivera-Romero, S. Konstantinidis, K. Denecke, E. Gabarrón, C. Petersen, M. Househ, M. Merolli, M. Á. Mayer

Ethical Considerations for Participatory Health through Social Media: Healthcare Workforce and Policy

Maker Perspectives 
Synopsis C. Petersen, V Subbian

Special Section on Ethics in Health Informatics

\section{Best Paper Selection Content summaries of:}

Antonio MG, Petrovskaya 0, Lau F. Is research on patient portals attuned to health equity? A scoping review. J Am Med Inform Assoc 2019 Aug 1;26(8-9):871-83

Lehmann CU, Petersen C, Bhatia H, Berner ES, Goodman KW. Advance directives and code status information exchange: a consensus proposal for a minimum set of attributes. Camb Q Healthc Ethics 2019 Jan;28(1):178-85

Pisani AR, Kanuri N, Filbin B, Gallo C, Gould M, Lehmann LS, Levine R, Marcotte JE, Pascal $B$, Rousseau D, Turner $S$, Yen S, Ranney ML. Protecting user privacy and rights in academic datasharing partnerships: principles from a pilot program at crisis text line. J Med Internet Res 2019 Jan 17;21(1):e11507

Section 1: Health Information Management

Survey

L. Riplinger, J. Piera-Jiménez, J. Pursley Dooling

Patient Identification Techniques - Approaches, Implications, and Findings

Synopsis M. Bloomrosen, E. S. Berner

Findings from the Health Information Management Section of the 2020 International Medical

Informatics Association Yearbook

\section{Best Paper Selection}

\section{Content summaries of:}

Hosseini M , Faiola A, Jones J, Vreeman DJ, Wu H, Dixon BE. Impact of document consolidation on healthcare providers' perceived workload and information reconciliation tasks: a mixed methods study. J Am Med Inform Assoc 2019;26(2):134-42

Yeung T. Local health department adoption of electronic health records and health information exchanges and its impact on population health. Int J Med Inform 2019;128:1-6

Souza J, Santos JV, Canedo VB, Betanzos A, Alves D, Freitas A. Importance of coding co-morbidities for APR-DRG assignment: Focus on cardiovascular and respiratory diseases. Health Inf Manag 2020;49(1):47-57 Hannigan A, Villarroel N, Roura M, LeMaster J, Basogomba A, Bradley C, MacFarlane A. Ethnicity recording in health and social care data collections in Ireland: where and how is it measured and what is it used for? Int J Equity Health 2019;19(1):2

Section 2: Human Factors and Organizational Issues

Survey

H. Hochheiser, R. S. Valdez

Human-Computer Interaction, Ethics, and Biomedical Informatics

Synopsis Y. Senathirajah, S. Pelayo

Human Factors and Organizational Issues

Best Paper Selection

\section{Content summaries of:}

Lee JY, van Karnebeek CDM, Wasserman WW. Development and user evaluation of a rare disease gene prioritization workflow based on cognitive ergonomics. J Am Med Inform Assoc 2019;26(2):124-33

Wang J, Liang H, Kang H, Gong Y. Understanding health information technology induced medication safety events by two conceptual frameworks. Appl Clin Inform 2019;10:158-67

Patterson ES, Su G, Sarkar U. Reducing delays to diagnosis in ambulatory care settings: A macrocognition perspective. Appl Ergon2020;82:102965 
Section 3: Clinical Information Systems

Survey U. H. Hübner, N. Egbert, G. Schulte

Clinical Information Systems - Seen through the Ethics Lens

Working Group Contribution F. Martin-Sanchez, R. Bellazzi, V. Casella, W. Dixon, G. Lopez-Campos, N. Peek

Progress in Characterizing the Human Exposome: a Key Step for Precision Medicine

Synopsis W. O. Hackl, A. Hoerbst

Trends in Clinical Information Systems Research in 2019

Best Paper Selection Content summaries of:

Gordon WJ, Wright A, Aiyagari R, Corbo L, Glynn RJ, Kadakia J, Kufahl J, Mazzone C, Noga J,

Parkulo M, Sanford B, Scheib P, Landman AB. Assessment of employee susceptibility to phishing attacks at US health care institutions. JAMA Netw open 2019;2(3):e190393

Hill BL, Brown R, Gabel E, Rakocz N, Lee C, Cannesson M, Baldi P, Loohuis LO, Johnson R, Jew B, Maoz U, Mahajan A, Sankararaman S, Hofer I, Halperin E. An automated machine learning-based model predicts postoperative mortality using readily-extractable preoperative electronic health record data. Br J Anaesth 2019;123(6):877-86

Shen N, Bernier T, Sequeira L, Strauss J, Silver MP, Carter-Langford A, Wilier, D. Understanding the patient privacy perspective on health information exchange: A systematic review. Int I Med Inform 2019:125:1-12

Section 4: Sensor, Signal and Imaging Informatics

Survey $\quad$ A. Choudhary, L. Tong, Y. Zhu, M. D. Wang

Advancing Medical Imaging Informatics by Deep Learning-Based Domain Adaptation

Synopsis W. Hsu, C. Baumgartner, T. Deserno

Notable Papers and Trends from 2019 in Sensors, Signals, and Imaging Informatics

Best Paper Selection Content summaries of:

Armanious K, Jiang C, Fischer M, Küstner T, Hepp T, Nikolaou K, Gatidis S, Yang B. MedGAN: Medical image translation using GANs. Comput Med Imaging Graph 2020;79:101684

Chandra BS, Sastry CS, Jana S. Robust heartbeat detection from multimodal data via CNN-based generalizable information fusion. IEEE Trans Biomed Eng 2019; 66(3):710-7

de Vos BD, Berendsen FF, Viergever MA, Sokooti H, Staring M, Išgum I. A deep learning framework for unsupervised affine and deformable image registration. Med Image Anal 2019;52:128-43

Zhu T, Pimentel MAF, Clifford GD, Clifton DA. Unsupervised Bayesian inference to fuse biosignal sensory estimates for personalizing care. IEEE J Biomed Health Inf 2019;23(1):47-58 
IV

Section 5: Decision Support

Survey I. Jankovic, J. H. Chen

Clinical Decision Support and Implications for the Clinician Burnout Crisis

Synopsis C. Duclos, J. Bouaud

Pragmatic Considerations on Clinical Decision Support from the 2019 literature

Best Paper Selection Content summaries of:

Hendriks MP, Verbeek XAAM, van Vegchel T, van der Sangen MIC, Strobbe LA, Merkus JWS,

Zonderland HM, Smorenburg CH, Jager A, Siesling S. Transformation of the National Breast Cancer Guideline Into Data-Driven Clinical Decision Trees. JCO Clin Cancer Inform 2019;3:1-14

Kamišalić A, Riaño D, Kert S, Welzer T, Nemec Zlatolas L. Multi-level medical knowledge formalization to support medical practice for chronic diseases. Data \& Knowledge Engineering 2019;119:36-57

Khalifa M, Magrabi F, Gallego B. Developing a framework for evidence-based grading and assessment of predictive tools for clinical decision support. BMC Med Inform Decis Mak 2019;19(1):207

Section 6: Knowledge Representation and

Management

Survey

\section{P. N. Robinson, M. A. Haendel}

Ontologies, Knowledge Representation, and Machine Learning for Translational Research:

Recent Contributions

Synopsis F. Dhombres, J. Charlet

Design and Use of Semantic Resources: Findings from the Section on Knowledge Representation and Management of the 2020 International Medical Informatics Association Yearbook

Best Paper Selection Content summaries of:

Burek $\mathrm{P}$, Scherf N, Herre H. Ontology patterns for the representation of quality changes of cells in time.

J Biomed Semantics 2019;10(1):16

Denaxas S, Gonzalez-Izquierdo A, Direk K, Fitzpatrick NK Fatemifar G, Baneriee A, Dobson RJB, Howe L, Kuan V, Lumbers RT, Pasea L, Patel RS, Shah AD, Hingorani AD, Sudlow C, Hemingway $\mathrm{H}$. UK phenomics platform for developing and validating electronic health record phenotypes: CALIBER. J Am Med Inform Assoc 2019;26(12):1545-59

Rector A, Schulz S, Rodrigues J-M, Chute CG, Solbrig H. On beyond Gruber: "Ontologies" in today's biomedical information systems and the limits of OWL. J Biomed Inform: X 2019 Jun 1;2:100002

Shen F, Zhao Y, Wang L, Mojarad MR, Wang Y, Liu S, Liu H. Rare disease knowledge enrichment through a data-driven approach. BMC Med Inform Decis Mak 2019;19(1):32

Section 7: Consumer Health Informatics and Education

Survey T. Eyers, Y. Krastev

Ethics in Surgical Innovations from the Patient Perspective

Synopsis P. Staccini, A. Y. S. Lau

Social Media, Research, and Ethics: Does Participant Willingness Matter?

Best Paper Selection Content summary of:

Reuter K, Zhu Y, Angyan P, Le N, Merchant AA, Zimmer M. Public concern about monitoring twitter users and their conversations to recruit for clinical trials: survey study. J Med Internet Res 2019 Oct 30;21(10):e15455 
Section 8: Bioinformatics and

Translational Informatics

Survey X. M. Fernández

Untangling Data in Precision Oncology - A Model for Chronic Diseases?

Synopsis M. Smail-Tabbone, B. Rance

Contributions from the 2019 Literature on Bioinformatics and Translational Informatics

Content summaries of:

Béal J, Montagud A, Traynard P, Barillot E, Calzone L. Personalization of logical models with multiomics data allows clinical stratification of patients. Front Physiol 2019 Jan 24;9:1965

Chen ML, Doddi A, Royer J, Freschi L, Schito M, Ezewudo M, Kohane IS, Beam A, Farhat M. Beyond multidrug resistance: Leveraging rare variants with machine and statistical learning models in Mycobacterium tuberculosis resistance prediction. EBioMedicine 2019 May;43:356-69

Kim K, Baik H, Jang CS, Roh JK, Eskin E, Han B. Genomic GPS: using genetic distance from individuals to public data for genomic analysis without disclosing personal genomes. Genome Biol 2019 Dec;20(1):175

Marttinen M, Paananen J, Neme A, Vikram M, Takalo M, Natune T, Paldanius KMA, Mäkinen P, Bremang M, Kurki MI, Rauramaa T, Leinonen V, Soininen H, Haapasalo A, Pike I, Hiltunen M. A multiomic approach to characterize the temporal sequencein Alzheimer's disease-related pathology. Neurobiol Dis 2019;124:45468

Section 9: Clinical Research Informatics

Survey

\section{A. Solomonides}

Review of Clinical Research Informatics

C. Daniel, D. Kalra

Synopsis Clinical Research Informatics

Best Paper Selection Content summaries of:

Paddock S, Abedtash H, Zummo J, Thomas S. Proof-of-concept study: Homomorphically encrypted data can support real-time learning in personalized cancer medicine. BMC Med Inform Decis Mak 2019 Dec 4;19(1):255

Suchard MA, Schuemie MJ, Krumholz HM, You SC, Chen R, Pratt N, Reich CG, Duke J, Madigan D, Hripcsak G, Ryan PB. Comprehensive comparative effectiveness and safety of first-line antihypertensive drug classes: a systematic, multinational, large-scale analysis. Lancet 2019 Nov 16;394(10211):1816-26

Yu Y, Ruddy KJ, Hong N, Tsuji S, Wen A, Shah ND, Jiang G. ADEpedia-on-OHDSI: A next generation pharmacovigilance signal detection platform using the OHDSI common data model. J Biomed Inform 2019 
VI

(C) 2020

IMIA and Georg Thieme Verlag KG

Section 10: Natural Language Processing

Survey U. Hahn, M. Oleynik

Medical Information Extraction in the Age of Deep Learning

Synopsis C. Grouin, N. Grabar

A Year of Papers Using Biomedical Texts: Findings from the Section on Clinical Natural Language Processing of the International Medical Informatics Association Yearbook

Content summaries of:

Best Paper Selection

Guan J, Li R, Yu S, Zhang X. A Method for Generating Synthetic Electronic Medical Record Text. IEEE/ACM Trans Comput Biol Bioinform 2019

Lee J, Yoon W, Kim S, Kim D, Kim S, Ho So C, Kang J. BioBERT: a pre-trained biomedical language representation model for biomedical text mining. Bioinformatics 2019;36(4):1234-40

Rosemblat G, Fiszman M, Shin D, Kılıçoğlu H. Towards a characterization of apparent contradictions in the biomedical literature using context analysis. J Biomed Inform 2019;98:103275

Section 11: Public Health and

Epidemiology Informatics

Survey

D. L. Buckeridge

Precision, Equity, and Public Health and Epidemiology Informatics - A Scoping Review

Synopsis S. Cossin, R. Thiébaut

Public Health and Epidemiology Informatics: Recent Research Trends. Moving toward Public Health Data Science

Best Paper Selection Content summaries of:

Bruzelius E, Le M, Kenny A, Downey J, Danieletto M, Baum A, Doupe P, Silva B, Landrigan PJ, Singh P. Satellite images and machine learning can identify remote communities to facilitate access to health services. I Am Med Inform Assoc 2019;26(8-9):806-12

Feldman J, Thomas-Bachli A, Forsyth J, Patel ZH, Khan K. Development of a global infectious disease activity database using natural language processing, machine learning, and human expertise. J Am Med Inform Assoc 2019;26(11):1355-9

Section 12: Cancer Informatics

Survey

A. C. Griffin, U. Topaloglu, S. Davis, A. E. Chung

From Patient Engagement to Precision Oncology: Leveraging Informatics to Advance Cancer Care

Synopsis J. L. Warner, D. Patt

Cancer Informatics in 2019: Deep Learning Takes Center Stage

Best Paper Selection Content summaries of:

Ardila D, Kiraly AP, Bharadwaj S, Choi B, Reicher JJ, Peng L, Tse D, Etemadi M, Ye W, Corrado

$G$, Naidich DP, Shetty $S$. End-to-end lung cancer screening with three-dimensional deep learning on low-dose chest computed tomography. Nat Med 2019 May 20;25:954-61

Campanella G, Hanna MG, Geneslaw L, Miraflor A, Werneck Krauss Silva V, Busam KJ, Brogi E, Reuter VE, Klimstra DS, Fuchs TJ. Clinical-grade computational pathology using weakly supervised 
Research \& Education L. Di Marco, J. Breton, D. K. Martin, P. Morand, P. Gillois

Freedom of Master's Degree Students to Study in Health Curricula: Switching to Optimized

Blended Learning as a Solution!

History of Medical Informatics

C. A. Kulikowski

Donald A. B. Lindberg: Inspiring Leader and Visionary in Biomedicine, Healthcare, and Informatics

Information on IMIA

Welcome to IMIA

Honorary Fellows

IMIA Member Societies

Institutional Members

Addresses of IMIA Member Societies

Information on IMIA Regions

Information on APAMI (Asia Pacific Association for Medical Informatics)

Information on Helina (African Region)

284

Information on IMIA-LAC (Health Informatics Association for Latin-America and Caribbean)

Information on MENAHIA (Middle East and North African Association for Health Informatics)

Information on NAMI (North-American Medical Informatics)

295

Information on EFMI (European Federation For Medical Informatics)

IMIA Yearbook Special Topics 